\title{
Assessing the nutritional status of elderly Chinese lung cancer patients using the Mini-Nutritional Assessment $\left(\mathrm{MNA}^{\circledR}\right)$ tool
}

This article was published in the following Dove Press journal:

Clinical Interventions in Aging

4 March 2013

Number of times this article has been viewed

\author{
Lei Zhangl,* \\ Yanjun Sul,* \\ Chen Wang ${ }^{2}$ \\ Yongsheng Sha' \\ Hong Zhu ${ }^{3}$ \\ Shumin $\mathrm{Xie}^{4}$ \\ Sabrina Kwauk ${ }^{5}$ \\ Jing Zhang ${ }^{2}$ \\ Yunshou $\operatorname{Lin}^{2}$ \\ Changli Wangl,* \\ 'Department of Thoracic Surgery, Key \\ Laboratory of Cancer Prevention and \\ Therapy, Tianjin Lung Cancer Center, \\ Tianjin Medical University Cancer \\ Institute and Hospital, Tianjin, \\ ${ }^{2}$ Tianjin Medical University, Tianjin, \\ ${ }^{3}$ Department of Public Health, \\ Tianjin Medical University, Tianjin, \\ ${ }^{4}$ Xiangya Medical School of Central- \\ South University, Changsha, People's \\ Republic of China; ${ }^{5}$ School of Public \\ Health, Harvard University, Boston, \\ Cambridge, MA, USA \\ *These authors contributed equally to \\ this work
}

Purpose: This study assessed the nutritional status of elderly Chinese lung cancer inpatients using a revised version of the Mini-Nutritional Assessment $\left(\mathrm{MNA}^{\circledR}\right)$ tool.

Patients and methods: The revised version of the MNA tool was used to assess the nutritional status of 180 elderly Chinese lung cancer inpatients prior to their scheduled surgery between June 2010 and July 2011. Patients' demographic data, anthropometric parameters, and biochemical markers were collected and analyzed.

Results: Among the 180 inpatients who underwent the MNA, 9\% were malnourished (MNA score $<19$ ), 33\% were at risk of malnutrition (MNA score 19-23), and 58\% were well nourished (MNA score $\geq 24$ ). There was significant correlation between the MNA scores of patients who were malnourished, at risk of malnutrition, and well nourished $(P<0.001)$, as well as between total MNA score and most MNA questions. The three patient groups with different nutritional statuses differed significantly in their responses to anthropometrics and global, diet, and subjective assessments.

Conclusion: Incidence rates of malnutrition prior to surgery are high among elderly Chinese lung cancer inpatients. The revised MNA is a valid and reliable tool that can be used to assess and prevent malnutrition among these inpatients.

Keywords: malnutrition, MNA-SF, nutrition, inpatients, diet

\section{Introduction}

Malnutrition is a common and serious problem among geriatric patients, particularly for those who are diagnosed with lung cancer caused by declined functional reserve of visceral organs, decreased stability of the internal environment, and effects of acute or chronic diseases. Malnutrition can lead to increased risk of surgery, decreased quality of life, increased incidence of postoperative complications, increased fatality rate, and decreased survival rate among elderly lung cancer inpatients. ${ }^{1,2}$ Nutrition support has also been reported to improve the perioperative nutritional status and reduce the severity of postoperative complications in lung cancer. ${ }^{3}$

In the People's Republic of China, the number of elderly lung cancer inpatients is increasing at a rapid rate; thus, there is a great need to develop a tool that can accurately and effectively assess the nutritional status of these patients. The MiniNutritional Assessment $\left(\mathrm{MNA}^{\circledR}\right)$ is a tool that is widely used in the USA and Europe to evaluate patients' nutritional status. This study examines the use of the MNA and short-form MNA (MNA-SF) (with a revised scoring system to better suit the elderly Chinese population ${ }^{5}$ ) in assessing the nutritional status of elderly Chinese lung cancer inpatients prior to scheduled surgery.
Correspondence: Changli Wang Department of Thoracic Surgery, Tianjin Medical University Cancer Institute and Hospital, Key Laboratory of Cancer Prevention and Therapy, Tianjin, People's Republic of China 300060 Tel +862223340123 Fax +8622 23359984 Email chinaray728@gmail.com 


\section{Material and methods}

\section{Participants}

A total of 180 elderly Chinese lung cancer inpatients (120 men and 60 women) aged 60 and older were randomly selected from the Tianjin Medical University Cancer Institute and Hospital between June 2010 and July 2011. All patients were scheduled for surgery and assessed within 5 days of hospital admission.

\section{MNA/MNA-SF scoring system}

The original MNA and MNA-SF scoring systems developed by Guigoz ${ }^{4}$ were revised to account for differences in height, weight, and dietary behaviors between Asian and Western populations. For the present study, Guigoz's cutoff point of $<17$ for malnutrition was changed to $<19$, thereby modifying the overall scoring system for assessing patients' nutritional status (maximum score $=30$ ), thus: a score $\geq 24$ would indicate that a patient was well nourished, a score in the range 19-23 would indicate that a patient was at risk of malnutrition, and a score $<19$ would indicate that a patient was malnourished. ${ }^{5}$ In addition, the body mass index (BMI) $(\mathrm{kg} /$ $\mathrm{m}^{2}$ ) ranges were adjusted to align with the following scores: $<18.50 \mathrm{~kg} / \mathrm{m}^{2}=0\left(\mathrm{vs}<19.00 \mathrm{~kg} / \mathrm{m}^{2}=0\right), 18.50-21.25 \mathrm{~kg} / \mathrm{m}^{2}=1$ (vs $19.00-21.00 \mathrm{~kg} / \mathrm{m}^{2}=1$ ), $21.25-24.00 \mathrm{~kg} / \mathrm{m}^{2}=2$ (vs $\left.21.00-23.00 \mathrm{~kg} / \mathrm{m}^{2}=2\right),>24.00 \mathrm{~kg} / \mathrm{m}^{2}=3\left(\mathrm{vs}>23.00 \mathrm{~kg} / \mathrm{m}^{2}=3\right.$ ). Finally, in assessing dietary behaviors, cheese, which is infrequently consumed by the Chinese population, was replaced with soy and peanut milk. The maximum score for the MNA$\mathrm{SF}$ is 14 , where a score of 12 or more reflects a well-nourished nutritional status.

\section{Data collection}

Patients' demographic data, including age, sex, and smoking history (eg, date started smoking, number of cigarettes smoked per day, date ceased smoking), were collected by clinically trained nurses. Anthropometric parameters and biochemical markers were determined based on previous research. ${ }^{5}$ Biochemical markers were provided by clinical laboratories at the Tianjin Medical University Cancer Institute and Hospital, and reference values of biochemical markers were modified to assess the nutritional status of hospitalized patients.

\section{Ethics}

All protocols used in this study were approved by the Tianjin Cancer Institute and Hospital. All nurses and patients participating in this study were informed about the objectives of the study and signed an informed consent document prior to participating.

\section{Statistical analysis}

SPSS (v 17.0; IBM, Armonk, New York, NY, USA) software was used to conduct all statistical analyses. Means, standard deviations, cross tabulation, and frequency tables were used as descriptive statistics. Spearman's correlation coefficients were used to calculate correlation significance. Analysis of variance for normally distributed dates and nonparametric methods, such as the Wilcoxon two-sample test and the Kruskal-Wallis test were used to make statistical comparisons. All results are presented as means \pm standard deviation. A $P$ value of $<0.05$ was considered statistically significant.

\section{Results \\ Participants}

Average age of the 180 sample patients was $67.3 \pm 5.0$ years, with a range of 60 85 years. Across all patients assessed, 9\% $(\mathrm{n}=17)$ were malnourished (MNA score $<19), 33 \%(\mathrm{n}=59)$ were at risk of malnutrition (MNA score 19-23), and 58\% $(\mathrm{n}=104)$ were well nourished (MNA score $\geq 24$ ). Mean MNA score was $23.8 \pm 3.6$ with a range of 10 to 30 . Average MNA-SF score was $11.5 \pm 2.3$ with a range of 4 to 15 . Among all patients assessed, $4 \%(n=7)$ had a BMI of greater than $30 \mathrm{~kg} / \mathrm{m}^{2}$ and $7 \%(\mathrm{n}=13)$ had a BMI of less than $20 \mathrm{~kg} / \mathrm{m}^{2}$.

To measure the criterion-related validity of the MNA, the MNA scores and anthropometric data were collected and analyzed. Significant correlations were found between BMI and MNA scores $(P=0.000)$; MNA scores of well-nourished, at risk of malnutrition, and malnourished patients $(P<0.001)$; the BMI of well-nourished and malnourished patients $(P<0.05)$; and the calf circumference $(\mathrm{CC})$ of well-nourished and at risk of malnutrition patients with malnourished patients $(P<0.05)$. All results are summarized in Table 1.

\section{Correlations between total MNA score and MNA questions}

Reliability was measured as homogeneity using Cronbach's $\alpha$ coefficient and item-to-total score correlations. Significant correlations between total MNA score and MNA questions were found for all questions with the exception of four related to neuropsychological problems, independence, skin problems, and number of meals eaten per day. Cronbach's $\alpha$ coefficient was 0.698 . The correlations between total MNA score and MNA questions are summarized in Table 2.

\section{MNA questions and their intercorrelations}

Significant correlations were found between different MNA questions. For example, declined food intake 
Table I Mini-Nutritional Assessment $\left(\mathrm{MNA}^{\circledR}\right)$ scores and anthropometry among 180 lung cancer patients categorized by nutritional status

\begin{tabular}{|c|c|c|c|c|}
\hline & $\begin{array}{l}\text { Whole group } \\
(n=180), \text { mean } \pm S D\end{array}$ & $\begin{array}{l}\text { Well nourished } \\
(n=104), \text { mean } \pm \text { SD }\end{array}$ & $\begin{array}{l}\text { At risk }(n=59), \\
\text { mean } \pm S D\end{array}$ & $\begin{array}{l}\text { Malnourished } \\
(n=17), \text { mean } \pm \text { SD }\end{array}$ \\
\hline MNA total (max score 30$)$ & $23.8 \pm 3.6$ & $26.3 \pm 1.5^{*, a}$ & $21.6 \pm 1.4^{*, a}$ & $16.2 \pm 2.4^{*, a}$ \\
\hline BMI $\left(\mathrm{kg} / \mathrm{m}^{2}\right)$ & $24.6 \pm 3.3$ & $25.5 \pm 3.0$ & $24.1 \pm 3.1$ & $21.2 \pm 3.7^{* *, \mathrm{~b}}$ \\
\hline SFT $(\mathrm{mm})$ & $15.7 \pm 7.6$ & $16.7 \pm 7.8$ & $14.3 \pm 6.9$ & $14.8 \pm 8.4$ \\
\hline $\operatorname{MAC}(\mathrm{cm})$ & $28.1 \pm 3.1$ & $28.6 \pm 2.9$ & $27.7 \pm 3.4$ & $26.4 \pm 3.1$ \\
\hline $\mathrm{CC}(\mathrm{cm})$ & $32.3 \pm 5.7$ & $33.1 \pm 5.7^{* *, c}$ & $32.0 \pm 5.4 * *, c$ & $28.8 \pm 5.8$ \\
\hline ALB $(g / L)$ & $45.9 \pm 8.1$ & $46.5 \pm 9.6$ & $44.5 \pm 4.0$ & $46.8 \pm 8.8$ \\
\hline LC $\left(10^{\circ} / \mathrm{L}\right)$ & $2.1 \pm 1.9$ & $2.0 \pm 0.8$ & $2.2 \pm 3.0$ & $1.8 \pm 0.7$ \\
\hline $\mathrm{HB}(g / L)$ & $137.1 \pm 20.9$ & $137.1 \pm 24.9$ & $139.0 \pm 13.1$ & $130.5 \pm 14.3$ \\
\hline
\end{tabular}

Notes: $* P<0.00$ I; $* * P<0.05$; ${ }^{2}$ Kruskal-Wallis test; ${ }^{b}$ compared with well nourished; ${ }^{c}$ compared with malnourished.

Abbreviations: ALB, albumin; BMI, body mass index; CC, calf circumference; HB, hemoglobin; LC, lymphocyte count; MAC, mid-arm circumference; SD, standard deviation; SFT, skin-fold thickness.

was strongly correlated with weight loss during the last 3 months $(r=0.538)$, self-perceived nutritional status $(r=0.485)$, and self-perceived health status $(r=0.482)$.

There was also a strong correlation between self-perceived nutritional status and self-perceived health status. In contrast, no significant correlations were linked to skin problems, number of meals eaten per day, and neuropsychological problems.

\section{MNA questions with a high frequency of zero scores}

MNA questions that had a high number of an assigned score of 0 provided key insights: $99 \%(n=178)$ of patients could consume their food independently, $44 \%$ (80) suffered

Table 2 Correlations of Mini-Nutritional Assessment $\left(\mathrm{MNA}^{\circledR}\right)$ questions to total MNA score $(n=180)$

\begin{tabular}{lll}
\hline MNA question & Spearman's $\boldsymbol{r}$ & $\boldsymbol{P}$ value \\
\hline Weight loss during the last 3 months & 0.67 & $*$ \\
Self-perceived health status & 0.65 & $*$ \\
Psychological stress & 0.64 & $*$ \\
Food intake declined & 0.63 & $*$ \\
Self-perceived nutritional status & 0.61 & $*$ \\
BMI & 0.49 & $*$ \\
Consumption of water & 0.37 & $*$ \\
Protein intake & 0.36 & $*$ \\
CC & 0.31 & $*$ \\
Mobility & 0.29 & $*$ \\
Three prescription drugs per day & 0.24 & $* *$ \\
Consumption of vegetables and fruit & 0.22 & $* *$ \\
Ability to eat & 0.17 & $* * *$ \\
MAC & 0.16 & $* * *$ \\
Neuropsychological problems & 0.10 & 0.17 \\
Independence & 0.09 & 0.21 \\
Number of meals eaten per day & 0.05 & 0.48 \\
Skin problems & 0.05 & 0.5 I \\
\hline
\end{tabular}

Notes: $* p<0.001 ; * * p<0.01$; $* * * p<0.05$.

Abbreviations: BMI, body mass index; CC, calf circumference; MAC, mid-arm circumference. psychological stress, 26\% (46) consumed low amounts of protein each day, $25 \%$ (45) had a CC $<31 \mathrm{~cm}, 15 \%$ (27) drank fewer than three cups of water per day, and 13\% (24) consumed fewer than three different types of fruits and vegetables per day.

\section{MNA subgroup questions related to anthropometrics, and global, diet, and subjective assessments}

Patients who were well nourished, at risk of malnutrition, and malnourished differed significantly in their responses to anthropometrics, and global, diet, and subjective assessments (Table 3). This suggests that all four aspects of the MNA contribute to the total MNA score and the nutritional status of the patients.

\section{Discussion}

Published findings on the nutritional status of lung cancer inpatients vary greatly in the medical literature. Some studies conclude that there is a high incidence of malnutrition among lung cancer inpatients. For example, Hollaus et $\mathrm{al}^{6}$ and Chauhan et $\mathrm{al}^{7}$ found that $10 \%-20 \%$ and $30 \%$ of patients suffered from malnutrition, respectively. In contrast, other studies have shown that malnutrition rates are overestimated in lung cancer patients. Jagoe et al reported that severe malnutrition was uncommon among lung cancer patients who were referred for surgery. ${ }^{8}$ However, in the present study, the incidence rate of malnutrition was found to be $42 \%$ among 180 lung cancer inpatients who were referred for surgery. The malnutrition or cachexia in these patients may have been caused by a slowdown in metabolism due to decreased organic functions, or absorption of the body's nutrients by malignant tumors before metastasis. ${ }^{9}$

This study also showed that there were significant correlations between MNA score and BMI $(P=0.000)$; the 
Table 3 Comparison of Mini-Nutritional Assessment $\left(M^{\circledR} A^{\circledR}\right)$ subgroup question scores among 180 lung cancer patients categorized by nutritional status

\begin{tabular}{|c|c|c|c|c|c|c|c|c|}
\hline \multirow[t]{2}{*}{$\begin{array}{l}\text { MNA subgroup } \\
\text { questions }\end{array}$} & \multicolumn{2}{|c|}{$\begin{array}{l}\text { Whole group } \\
(n=178)\end{array}$} & \multicolumn{2}{|c|}{$\begin{array}{l}\text { Well nourished } \\
(n=104)\end{array}$} & \multicolumn{2}{|c|}{$\begin{array}{l}\text { At risk } \\
(n=59)\end{array}$} & \multicolumn{2}{|c|}{$\begin{array}{l}\text { Malnourished } \\
(n=17)\end{array}$} \\
\hline & Mean & $95 \% \mathrm{Cl}$ & Mean & $95 \% \mathrm{Cl}$ & Mean & $95 \% \mathrm{Cl}$ & Mean & $95 \% \mathrm{Cl}$ \\
\hline $\begin{array}{l}\text { I MNA } \\
\text { anthropometrics }\end{array}$ & 6.48 & $6.24-6.72$ & $7.25^{*}$ & $7.06-7.44$ & $5.92 *$ & $5.56-6.28$ & $3.53 *$ & $2.53-4.53$ \\
\hline $\begin{array}{l}\text { II MNA global } \\
\text { assessment }\end{array}$ & 6.80 & $6.62-6.99$ & $7.43^{*}$ & $7.26-7.61$ & $6.05^{*}$ & $5.78-6.33$ & $5.50 *$ & $4.85-6.15$ \\
\hline $\begin{array}{l}\text { III MNA dietary } \\
\text { assessment }\end{array}$ & 7.65 & $7.49-7.80$ & $8.17^{*}$ & $8.04-8.31$ & $7.15^{*}$ & $6.93-7.37$ & $6.09 *$ & $5.48-6.70$ \\
\hline $\begin{array}{l}\text { IV MNA subjective } \\
\text { assessment }\end{array}$ & 2.86 & $2.70-3.01$ & $3.4 I^{*}$ & $3.29-3.53$ & $2.32 *$ & $2.07-2.57$ & $1.28^{*}$ & $0.83-1.74$ \\
\hline
\end{tabular}

Notes: Kruskal-Wallis test. $* P<0.05$.

Abbreviation: $\mathrm{Cl}$, confidence interval.

MNA scores of well-nourished, at risk of malnutrition, and malnourished patients $(P<0.001)$; the BMI of wellnourished and malnourished patients $(P<0.05)$; and the $\mathrm{CC}$ of well-nourished and at-risk of malnutrition patients with malnourished patients $(P<0.05)$. These results suggest that the MNA has good criterion-related validity. Secondly, all but four MNA questions (neuropsychological problems, independence, skin problems, and number of meals eaten per day) were significantly correlated to total MNA score. This shows that the MNA is a reliable instrument (Cronbach's $\alpha$ coefficient $=0.698$ ) for nutritional assessment. In addition, well-nourished, at risk of malnutrition, and malnourished patients differed significantly in their responses to MNA subgroup questions related to anthropometrics, and global, diet, and subjective assessments (Table 3). All these findings are supported by existing studies, suggesting that the MNA (with a revised scoring system to better suit the elderly Chinese population) is a valid and reliable diagnostic tool with which to assess the nutritional status of elderly Chinese lung cancer inpatients. ${ }^{5,10}$

No significant correlations were found between total MNA score and MNA questions related to neuropsychological problems and independence (Table 2). Studies conducted by Soini et $\mathrm{al}^{10}$ also found that independence was correlated with total MNA score, as nurses or family members helped feed patients. However, neuropsychological problems were strongly correlated to total MNA score in Soini and Murphy's studies. ${ }^{10,11}$ The differences between these findings and those of the present study may be due to the fact that, in our study, $99 \%(n=178)$ of patients could consume their food independently. Additionally, in our study, preliminary evaluations were carried out before surgery, and some patients with neuropsychological problems may have been transferred to receive neuropsychological treatment instead of undergoing surgery. As such, the lack of cooperation from patients with neuropsychological problems may increase their risk of postoperative complications and death.

\section{Conclusion}

The MNA is a valid and reliable diagnostic tool that can be used to identify elderly lung cancer inpatients who are malnourished, as well as those who are at risk for malnutrition. The high incidence rates of preoperative malnutrition and risk of malnutrition among elderly Chinese lung cancer inpatients highlights the need for further investigations to determine the relationship between nutritional status and prognosis of these patients.

\section{Disclosure}

The authors declare no conflicts of interest in this work.

\section{References}

1. Burnier M, Fricker AF, Hayoz D, Nussberger J, Brunner HR. Pharmacokinetic and pharmacodynamic effects of YM087, a combined V1/V2 vasopressin receptor antagonist in normal subjects. Eur J Clin Pharmacol. 1999;55(9):633-637.

2. Decaux G. Long-term treatment of patients with inappropriate secretion of antidiuretic hormone by the vasopressin receptor antagonist conivaptan, urea, or furosemide. Am J Med. 2001;110(7):582-584.

3. Shintani Y, Ikeda N, Matsumoto T, et al. Nutritional status of patients undergoing chemoradiotherapy for lung cancer. Asian Cardiovasc Thorac Ann. 2012;20(2):172-176.

4. GuigozY, Vellas B, Garry P. Assessing the nutritional status of the elderly: the Mini Nutritional Assessment as part of the geriatric evaluation. Nutr Rev. 1996;54:559-565.

5. Lei Z, Qingyi D, Feng G, Chen W, Hock RS, Changli W. Clinical study of mini-nutritional assessment for older Chinese inpatients. J Nutr Health Aging. 2009;13(10):871-875.

6. Hollaus PH, Wilfing G, Wurnig PN, Pridun NS. Risk factors for the development of postoperative complications after bronchial sleeve resection for malignancy: a univariate and multivariate analysis. Ann Thorac Surg. 2003;75(3):966-972. 
7. Chauhan A, Siddall V, Wilcock A, Mallawathantri S, Baldwin DR, Johnston ID. NICE guidance for screening for malnutrition: implications for lung cancer services. Thorax. 2007;62(9):835.

8. Jagoe RT, Goodship TH, Gibson GJ. Nutritional status of patients undergoing lung cancer operations. Ann Thorac Surg. 2001;71(3):929-935.

9. Holroyde CP, Reichard GA Jr. General metabolic abnormalities in cancer patients: anorexia and cachexia. Surg Clin N Am. 1986;66(5):947-956.
10. Soini H, Routasalo P, Lagström H. Characteristics of the MiniNutritional Assessment in elderly home-care patients. Eur J Clin Nutr. 2004;58(1): 64-70.

11. Murphy MC, Brooks CN, New SA, Lumbers ML. The use of the Mini-Nutritional Assessment (MNA) tool in elderly orthopaedic patients. Eur J Clin Nutr. 2000;54(7):555-562.

\section{Publish your work in this journal}

Clinical Interventions in Aging is an international, peer-reviewed journal focusing on evidence-based reports on the value or lack thereof of treatments intended to prevent or delay the onset of maladaptive correlates of aging in human beings. This journal is indexed on PubMed Central, MedLine, the American Chemical Society's 'Chemical Abstracts Ser-

\section{Dovepress}

vice' (CAS), Scopus and the Elsevier Bibliographic databases. The manuscript management system is completely online and includes a very quick and fair peer-review system, which is all easy to use. Visit $\mathrm{http}: / /$ www.dovepress.com/testimonials.php to read real quotes from published authors.

Submit your manuscript here: http://www.dovepress.com/clinical-interventions-in-aging-journal 